\title{
Analysis of the Main Factors Affecting National Vulnerability based on Principal Component Analysis
}

\author{
Zhixing Song \\ School of North China Electric Power University, Baoding 071000, China. \\ 504115681@qq.com
}

Keywords: Principal component analysis; State’s fragility; Zambia; Syria.

\begin{abstract}
To analyze the impact of climate change on national stability, this paper established a national vulnerability model that was analyzed by principal component analysis. It proposes seven climate vulnerability risk indicators, including competition for local resources, insecurities and migration of life, extreme weather events and disasters, fluctuating food prices and supplies, transboundary water management, sea level rise and coast The combined effects of degradation and climate policy. The improved principal component analysis is used as a basic model for assessing national vulnerability. A new variable SF is introduced as a composite score for a country vulnerability. Through the eigenvectors, the main factors affecting the vulnerability can be obtained.
\end{abstract}

We selected eight countries with very different points to rank and compare the country's vulnerability calculated by our model to verify the usefulness of our model. We chose Syria as an assessment country to show the main factors affecting the country's vulnerability through our model. It can also be proved that when the country is not affected by these factors, it will not become so vulnerable. We chose Zambia as the analytical target. Then in Italy, for example, we focus on interventions in climate governance in Italy and make reasonable estimates of the cost of investment in Italy.

\section{Introduction}

\subsection{Background}

Climate change is a serious issue in the 21st century and a relatively threatening issue in our time. Many of the negative effects of climate change are gradually affecting people's way of working and living. Climate change will also cause many potential natural hazards, and even lead to national turmoil. This time, we propose to use principal component analysis to study the country's vulnerability.

\subsection{Variable Description}

We set up seven indicators, and divide the seven comprehensive indicators into 18 specific factors, and classify them separately. The main 15 items are listed in the table. 
We will show the description of variables in Table 1.

Table 1 Variable Description

\begin{tabular}{c|c}
\hline Comprehensive score of state's fragility & SF \\
\hline Level of state's fragility & SFL \\
\hline Predict score & $\mathrm{PS}$ \\
\hline Total supply of water & $\mathrm{T}$ \\
\hline Renewable water & $\mathrm{Rw}$ \\
\hline Agricultural land & $\mathrm{Al}$ \\
\hline Irrigated area & $\mathrm{Ia}$ \\
\hline Forest coverage & $\mathrm{Fc}$ \\
\hline Unemployment rate & $\mathrm{Ur}$ \\
\hline Fishery industry & $\mathrm{Fi}$ \\
\hline Number of immigrants & $\mathrm{Noi}$ \\
\hline Total population & $\mathrm{Tp}$ \\
\hline Agricultural output & $\mathrm{Ao}$ \\
\hline Air pollution & $\mathrm{Ap}$ \\
\hline Greenhouse gases & $\mathrm{Ga}$ \\
\hline Diversity of fish & $\mathrm{Df}$ \\
\hline
\end{tabular}

\subsection{Our standards}

We found the Fragile State Index Heat Map, and the map shows whether a countryis stable, vulnerable or fragile. After the information inquiry,We chose the two lowest Totle between fragile countries and vulnerable country. Then we used our model to calculate their composite score as the dividing line between the degree of vulnerability we judge. The two selected countries after inquiries are Nigeria and Namibia. After our calculations, we have obtained our standard of judging the level of state's fragility, As shown in Table 2.

Table 2

\begin{tabular}{c|c}
\hline Standard & Judgement \\
\hline $\mathrm{SF}<=-2.228$ & Fragile \\
$-2.228<\mathrm{SF}<=-1.45$ & Vulnerable \\
$-1.45<\mathrm{SF}$ & Stable \\
\hline
\end{tabular}

\subsection{Direct or indirect effects}

Through the review of the data and our analysis, we found that: climate change has caused droughts, glaciers shrink, sea level rise, plants and animals decreased, directly affecting the development of fisheries, regional water reserves, forests and arable land and so on. These changes affect the irrigated area, the number of migrants, per capita water consumption and so on. Reduced water use, increased catastrophe indices and reduced arable land have contributed to increased fragility to climate conditions, which have directly increased the vulnerability of countries and have indirectly increased national vulnerability by reducing irrigated area, increasing unemployment and reducing gross national income. 
Table 3: Direct and indirect effects

\begin{tabular}{c|ccccccccc}
\hline Direct effects & T & Rw & AI & Fc & Fi & D & Ao & S & Df \\
\hline Indirect effects & Ia & Ur & GNI & Noi & Tp & Cp & P & AP & Ga \\
\hline
\end{tabular}

\section{State Fragility in Syria}

Through our data inquiry and analysis of the ten most vulnerable countries, we decide to choose Syria as our evaluation city.In the view of many Western policymakers and commentators, the Syrian civil war was caused, in part, by anthropogenic climate change. Former US President Barack Obama claimed that climate change-related drought 'helped fuel the early unrest in Syria, which descended into civil war'. International organisations, official governmental and intergovernmental reports, academics and commentators of vario us political persuasions-all have argued similarly. So Syria is a country with a good indication that climate change will affect the country's vulnerability.

\subsection{What is the impact of climate change}

We have inquired about the data of Syria of nearly 13 years. We do the principal component analysis for the remaining indexes. In the calculation process, we get the pie chart (Figure 1) of each principal component contribution. We can find that the first principal component accounts for the largest proportion, so we only consider the eigenvector of the first principal component here.

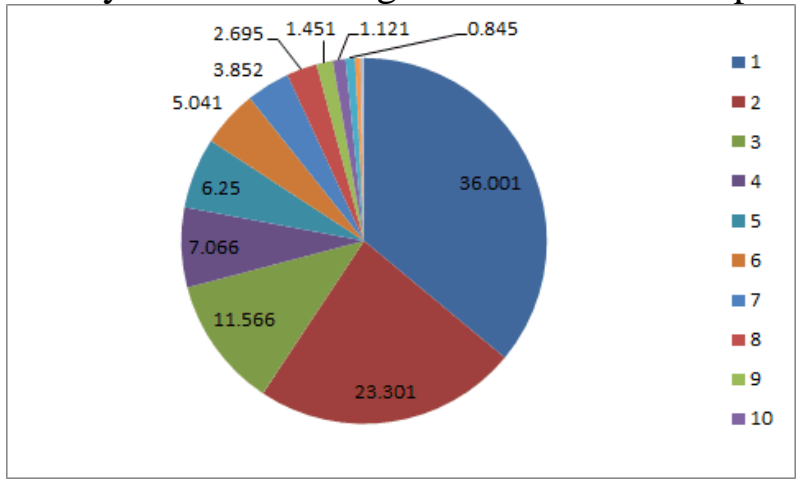

Figure 1 The pie chart of each principal component contribution

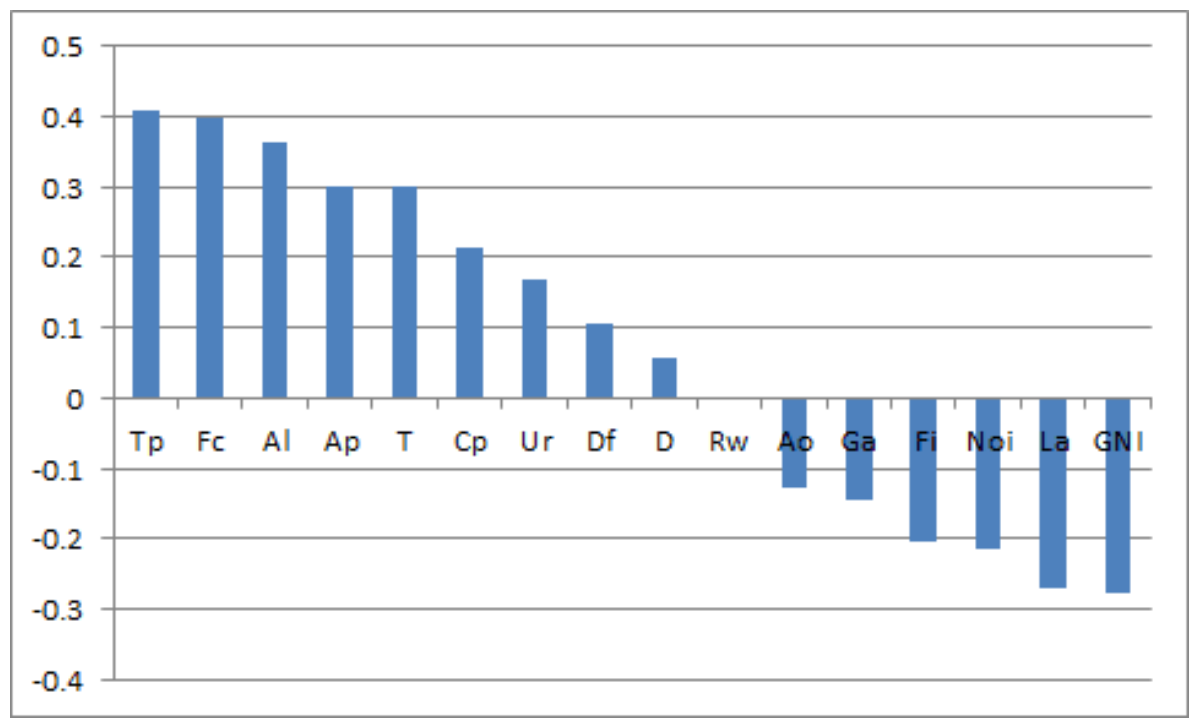

Figure 2 Eigenvector 
As can be seen from the Figure 2, climate change has a huge impact on the total population, forest coverage and agricultural land. And in the picture shows Disaster risk reduction progress score is also relatively low, so the disaster caused by climate change also has a tremendous impact on Syria. The reduction of forest coverage will cause soil and water loss, increase of dry land, and decrease of agricultural land, which will in turn result in the decrease of grain output. These effects have a huge impact on the population.

\subsection{Change the impact}

In the last section, we have given various factors that affect the fragility. We can reduce the impact of this factor on the country by reducing the fluctuation of the influencing factors in order to achieve the purpose of "without these effects." The change in state fragility is then judged by comparison with previous trends. After the calculation we got Figure 3:.

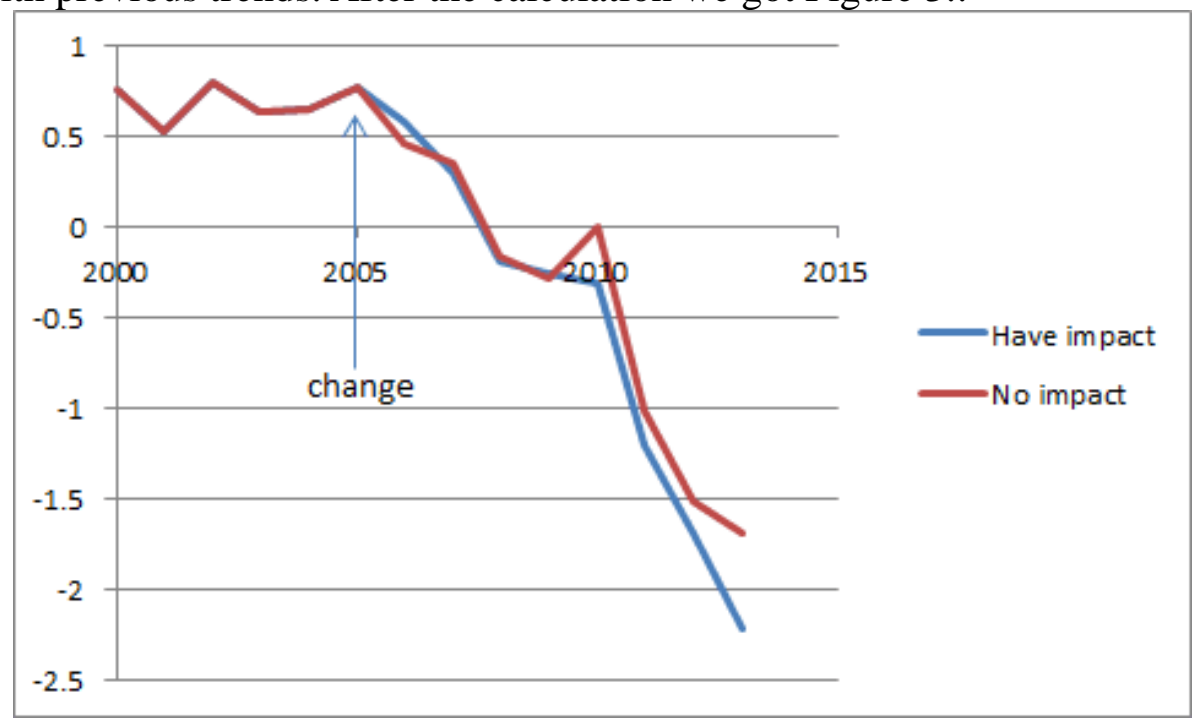

Figure 3 Change the impact

From Figure 3, we can see that after changing the value of the influencing factors, the degree of fragility in Syria has become noticeably better.The state may be less fragile without these effects.

\section{State Fragility in Zambia}

We chose Zambia as our evaluation country.

Zambia is endowed with considerable environmental assets, including 50 million hectares of forest and a rich wildlife estate and protected area system covering some $36 \%$ of the total land area. These natural resources are major contributors to GDP (e.g. mining, tourism, agriculture, forestry) amounts to $27 \%$ of national wealth in comparison to $2 \%$ in Overseas Economic Cooperation and Development countries and are critical to Zambia's effort to achieve sustainable development [1].

However, Zambia, which is well-resourced, still receives the impact of climate change. Vise president Inonge Wina said Zambia had not been spared by the Climate Change impacts. President Edgar Lungu says Climate Change can reverse developmental gains made by Zambia [2].Therefore, although Zambia is not a fragile country but a vulnerable state, the impact of climate change on it is also very large, so we decided to discuss Zambia's fragility.

After we looked up all the data in Zambia, we calculated with our model and got the charts of the SF (Figure4) and the charts of the eigenvectors (Figure5). From Figure 4 we can see that Zambia is becoming fragile year by year. Figure 5 shows that the main factor affecting the fragility of Zambia 
is: Tp; GNI; Al; Ao and Ap. Climate change has a direct impact on Al, Ao and Ap and then indirectly affects Tp and GNI, just as the vise president Inonge Wina put forward in her report [3].

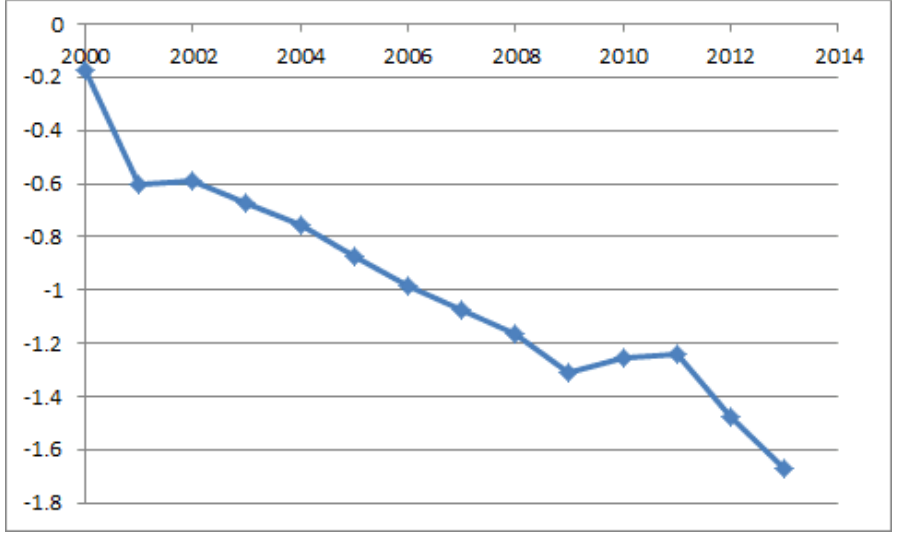

Figure 4 SF

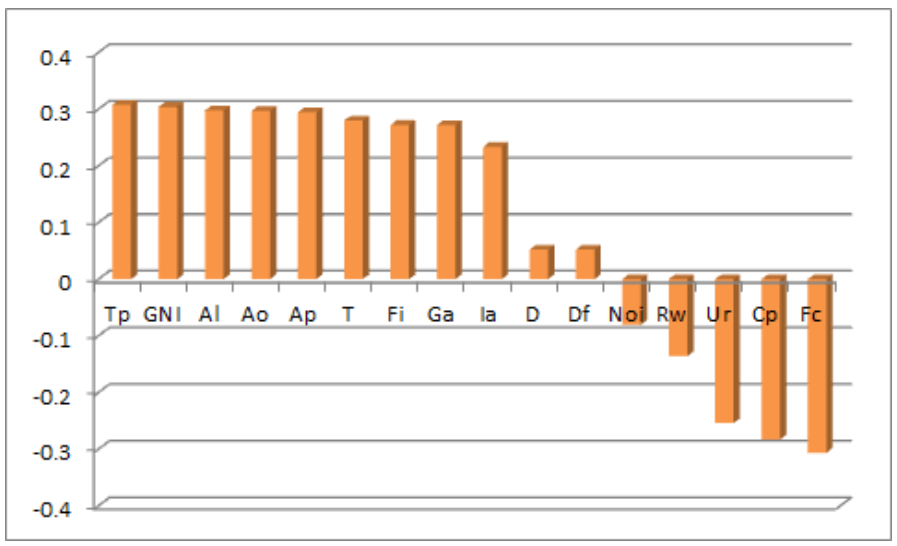

Figure 5 Eigenvectors

\section{Model Adaptability Test}

When analyzing the fragility of cities, because the scale of the city is much smaller than that of the country, there are many factors that we have considered did not exist. For example, there are no fishing industries in the coastal cities, and there is basically no forestry or forest coverage in the desert cities. This has greatly reduced the city's indicators, resulting in the city's floating far greater than the country, making the forecast results unstable. When predicting future trends of the index to be assessed, such as predicting the future stability of a country, the relative forecast of the city is not as good as the country's relative forecast.

\section{References}

[1] Environment and Climate Change Overview .United Nations Development Programme. Retrieved from http://www.zm.undp .org/content/zambia/en/home/ourwork/environmentandenergy/overview. html

[2]President Lungu says Climate Change affecting Zambia's developmentt. Lusaka Times. Retrieved from https://www.lusakatimes.com/2016/11/16/

president-lungu-says-climate-change-affecting-zambias-development/

[3] CLIMATE CHANGE IMPACTS ON ZAMBIA.TIMES OF ZAMBIA. Retrieved from
http://www.times.co.zm/?p=64567 